\title{
Electrophoretic Studies of Liver Protein
}

\author{
Report II. Studies on Liver Protein in Surgical \\ Gastric Diseases
}

By

\begin{abstract}
Toshio Sato, Satoru Akiba, Yoshihiko Miura, Hisanobu Ise, (佐 藤寿雄) (秋 葉 知) (三浦良彦) (伊勢 久信)
\end{abstract}

\section{Goro Kakizaki, Masao Yamanaka and Toshiyuki Taneichi}

(柿 崎 五 郎) (山中 雅夫) (種市敏行)

From Prof. M. Muto's Surgical Clinic, Tohoku University, Sendai, and the Surgical Department, National Hospital, Sendai

(Received for publication, June 22, 1959)

The writers have previously reported on electrophoresis applied to the study of liver protein in this Journal ${ }^{11}$, and here we will report on the liver protein fractions in surgical gastric diseases as analyzed by our method.

\section{EXPERIMENTAL \\ Methods}

For preparing the extract of the liver tissue protein (called simply liver protein hereunder) from liver specimens, the procedure for electrophoresis and identification of the fractions, the methods previously described $^{1)}$ were followed.

In discussing the behavior of the liver protein fractions, the state of the liver functions come into the question. For testing the liver functions in the experimental subjects, the serum icterus index, Bromsulphalein test and Takada's serum test were applied. Cases with the icterus index below 10 were evaluated as normal, those with $10-20$ as mild and over 20 as severely troubled in liver function; the cases with Bromsulphalein test ( 30 min. value) below 5 percent as normal, those with 5-20 percent as with mild and over 20 percent as with severe liver troubles. The cases with positive reaction in Takada's serum, were evaluated as severely disturbed in their liver function. In general evaluation, the cases showing positivity in any one of the above three tests were deemed as having mild disturbance $(+)$ and those with more than one positive reactions as severely disturbed in their liver function $(H)$.

\section{Results}

I. Liver protein fractions in the mild cases of gastric diseases 
Of the 108 cases tested, two of chronic gastritis and six of gastric ulcer showed more than 4 million in red cell count, more than 80 percent in hemoglobin content (Sahli), hematocrit value of 42-43 percent, normal level of liver function and were in good general conditions. These eight cases will be taken up first. In these cases only Ringer's solution or 5 percent glucose solution (500-1000 cc) was administered but no blood transfusion was applied before operation.

The measured contents of the liver protein fractions in these cases are given in Table I. The ranges and the mean values of 4.0-7.1 percent

TABLE I

Liver Protein Fraction Values in Mild Cases

\begin{tabular}{l|c|c|c|c|c}
\hline \multirow{2}{*}{ Case } & \multicolumn{5}{|c}{ Fraction values (\%) } \\
\cline { 2 - 6 } & Alb. & $\alpha$-Gl. & $\beta$-Gl. & $\zeta$-Gl. & $\gamma$-Gl. \\
\hline Gastritis & 4.0 & 16.2 & 47.5 & 21.1 & 11.2 \\
Gastritis & 5.2 & 16.1 & 46.5 & 19.3 & 12.9 \\
Gastric ulcer & 5.9 & 17.9 & 46.3 & 19.9 & 10.0 \\
Gastric ulcer & 5.9 & 19.0 & 45.2 & 20.8 & 9.1 \\
Gastric ulcer & 6.1 & 17.3 & 45.9 & 17.8 & 12.9 \\
Gastric ulcer & 6.2 & 14.0 & 49.2 & 20.5 & 10.1 \\
Gastric ulcer & 6.4 & 19.4 & 48.1 & 18.5 & 7.6 \\
Gastric ulcer & 7.1 & 16.6 & 48.9 & 18.4 & 9.0 \\
\hline \multirow{2}{*}{ Average } & $(4.0 \sim 7.1)$ & $(14.0 \sim 19.4)$ & $(45.2 \sim 49.2)$ & $(17.8 \sim 21.1)$ & $(7.1 \sim 12.9)$ \\
& 5.8 & 17.0 & 47.1 & 19.4 & 10.7
\end{tabular}

and 5.8 percent of albumin, $14.0-19.4$ percent and 17.8 percent of $\alpha$ globulin, 45.2-49.2 percent and 47.1 percent of $\beta$-globulin 17.8-21.1 percent and 19.4 percent of $\zeta$-globulin and $7.6-12.9$ percent and 10.7 percent of $\gamma$-globulin may be taken as the control value under normal liver function.

II. Liver Protein fractions in cases of gastric diseases

The results of electrophoresis obtained with six cases of chronic gastritis, 44 cases of gastric or duodenal ulcer and 50 cases of gastric cancer, compared with the values cited above, the $\alpha$-globulin value showed little change, the difference nearly always consisting in the changes in the albumin, $\beta$-, $\zeta$ - and $\gamma$-globulin values; so the $\beta$-globulin value was chosen as the main criterion in classifying the cases into five types, as follows:

Type I. Cases with all the values of the fractions within the control range.

Type II. Those with subnormal $\beta$-globulin values and high $\zeta$ globulin values, but the other fractions within the control range. 
Type III. Those with low $\beta$ - but high $\gamma$-globulin values, with the other fractions within the control range.

Type IV. Those with lowered $\beta$-globulin but raised albumin and $\gamma$-globulin values.

Type V. Those with lowered $\beta$-globulin and raised albumin values, the other fractions remaining within the control range.

(1) Liver protein fractions in cases of gastritis and gastric ulcer In the 50 cases of gastritis and ulcers, the liver protein fraction picture belonged to Type I in 26 cases, to Type II in four cases, to Type III in seven cases, to Type IV in nine and Type $\mathrm{V}$ in four cases. The maximum, the minimum and the mean values in individual cases by the Types were as summarized in Table II.

Among the 26 cases of Type I, two had pyloric stenosis, three had severe anaemia, and one had perforation, but excepting these, the other 20 cases showed excellent general conditions and no complicating symptoms. In these cases, all the tests for the liver function showed results well within the normal ranges.

The four Type II cases were also free of complications and showed good general conditions, but their $\beta$-globulin content showed the low values of $34.7-39.3$ percent, averaging 37.1 percent and their $\zeta$-globulin value was always above 22.8 percent, showing the high mean of 28.9 percent.

TABLE II

Liver Protein Fraction Values in Gastritis-Ulcer Cases

\begin{tabular}{|c|c|c|c|c|c|c|}
\hline \multirow{2}{*}{$\begin{array}{l}\text { Type of } \\
\text { cases }\end{array}$} & \multirow{2}{*}{$\begin{array}{c}\text { Number } \\
\text { of } \\
\text { cases }\end{array}$} & \multicolumn{5}{|c|}{ Fraction values (average, $\%$ ) } \\
\hline & & Albumin & $a$-Glob. & $\beta$-Glob. & $\zeta$-Glob. & $r$-Glob. \\
\hline Type I & 26 & $\stackrel{5.6}{(3.5 \sim 7.8)}$ & $\begin{array}{c}18.5 \\
(13.8 \sim 20.0)\end{array}$ & $\begin{array}{c}46.2 \\
(44.5 \sim 50.2)\end{array}$ & $\mid \begin{array}{c}19.6 \\
(16.8 \sim 21.3)\end{array}$ & $\left(\begin{array}{l}10.1 \\
(7.2 \sim 12.5)\end{array}\right.$ \\
\hline Type II & 4 & $(3.1 \sim 9.2)$ & $\begin{array}{c}16.7 \\
(11.1 \sim 20.7)\end{array}$ & $\begin{array}{c}37.1 \\
(34.7 \sim 39.3)\end{array}$ & $(22.8 \sim 40.3)$ & $\left(\begin{array}{c}9.9 \\
(8.1 \sim 10.8)\end{array}\right.$ \\
\hline Type III & 7 & $\left(4.8 \sim^{7.2} 8.4\right)$ & $\begin{array}{c}15.1 \\
(9.4 \sim 21.5)\end{array}$ & $\begin{array}{c}35.1 \\
(22.2 \sim 39.9)\end{array}$ & $\begin{array}{c}18.5 \\
(13.3 \sim 21.7)\end{array}$ & $\left(\begin{array}{c}24.1 \\
(14.0 \sim 43.4)\end{array}\right.$ \\
\hline Type IV & 9 & $\begin{array}{c}11.7 \\
(10.0 \sim 13.6)\end{array}$ & $\left(\begin{array}{c}14.6 \\
(8.8 \sim 19.0)\end{array}\right.$ & $\begin{array}{c}31.3 \\
(25.0 \sim 40.7)\end{array}$ & $(14.3 \sim 22.7)$ & $\left(\begin{array}{c}24.1 \\
(14.6 \sim 31.4)\end{array}\right.$ \\
\hline Type V & 4 & $\begin{array}{c}14.6 \\
(11.2 \sim 17.7)\end{array}$ & $\begin{array}{c}19.0 \\
(17.3 \sim 20.5)\end{array}$ & $\begin{array}{c}39.1 \\
(36.1 \sim 41.3)\end{array}$ & $\left(\begin{array}{c}18.0 \\
(15.8 \sim 20.7)\end{array}\right.$ & $\begin{array}{c}9.3 \\
(7.9 \sim 11.5)\end{array}$ \\
\hline
\end{tabular}

Of the seven Type III cases, five were suffering from hemorrhagic ulcers and showed seriously deteriorated general conditions, while another had pyloric stenosis and the remaining one had pulmonary tuberculosis in complication, both showing bad general conditions. In all these cases the $\beta$-globulin value was very low (mean value: $35.1 \%$ ) but the $\gamma$-globulin 
value very high (mean value: $24.1 \%$ ). Especially, in two of the cases, the $\beta$-globulin value was reduced to 22.2 percent and 26.0 percent and the $\gamma$-globulin value risen to 43.4 percent and 38.2 percent, respectively, showing a very peculiar tendency.

In these seven cases of Type III, the $\beta$-globulin value averaged by 12.0 percent below the control (or dropped by $25.4 \%$ in rate) and the $\uparrow$-globulin value averaged 13.4 percent above the control (or risen by $125.2 \%$ in rate). In these cases, however, all were found to be free of liver disturbances, except one which showed a slight disturbance in the liver function.

In Fig. 1. are shown the representative liver protein electrophoretic patterns of cases with hemorrhagic gastric ulcer belonging to Type III.
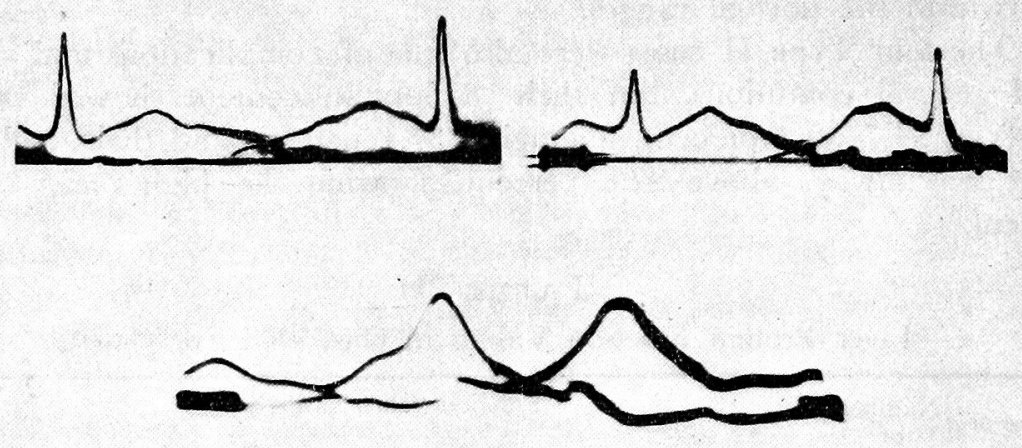

(Control Case).

Fig. 1. Electrophoretic patterns of Type III cases with hemorrhagic ulcer.

Of the nine cases belonging to Type IV, one showed good general conditions, but five had hemorrhagic ulcer, two had pyloric stenosis and one had lung tuberculosis in complication, these eight showing deteriorated general conditions. Especially, in the cases of hemorrhagic ulcer, the red cell count was lowered below 3.3 million, the hemoglobin content to below 70 percent (Sahli) and the serum protein to below $6.0 \mathrm{~g} . / \mathrm{dl}$., indicating serious conditions. 
In all these cases, the albumin content always rose above 10.0 percent, averaging 11.7 percent and cases with 13.4 percent and 13.6 percent of this value were observed, while the $\beta$-globulin value was below 40.7 percent in all cases, averaging 31.3 percent, especially notably low individual values of 25.0, 27.2 and 27.7 percents were observed. The $\gamma$-globulin value was supernormal, always exceeding 14.6 percent and averaging 24.1 percent. In particularly high cases, the value amounted to $27.2,30.6$ and 31.4 percents.

The mean value of albumin in these Type IV cases was higher by 5.9 percent than the control (or risen to $101.7 \%$ ), that of $\beta$ - and $\gamma$-globulins was lowered by 15.8 percent (or fallen by $33.5 \%$ in rate) and risen by 13.4 percent (or raised by $125.5 \%$ in rate), respectively. Among these nine cases, however, slight liver failure was observed in only two cases.

Of the four Type $\mathrm{V}$ cases, the general conditions were good in only one case, two of the other cases having hemorrhagic ulcers and one having pyloric stenosis.

In these cases, the albumin value always rose above 11.2 percent, averaging 14.6 percent, in one case rising to 17.7 percent, and the $\beta$ globulin value stood between 41.3 percent and 36.1 percent, averaging 39.1 percent below the mean control value.

In these four cases of Type $\mathrm{V}$, the mean albumin value was risen by 8.8 percent (or risen by $151.7 \%$ ), and the $\beta$-globulin value was lowered by 8.0 percent (or dropped by $16.9 \%$ ) from the mild case. In all these cases, the liver function tests showed normal values, except in one case with slight liver failure.

Among the above gastritis and gastric ulcer cases, 50 in total, Type I liver protein fraction picture was observed in 26 cases, that of Type II in four cases, of Type III in seven cases, of Type IV in nine cases and of Type V in four cases; 24 of the 30 Types I and II cases (80\%) showed good general conditions and 18 of the 20 Types III, IV and V cases $(90 \%)$ had complications.

(2) Liver protein fractions in cases of gastric cancer Among the 50 cases of gastric cancer, the liver protein fraction picture belong to Type I in 21 cases, to Type II in four cases, to Type III in 12 cases, to Type IV in seven and to Type $\mathrm{V}$ in six cases. The individual maximum, the minimum and the mean values of the liver protein fractions by the Types were as summarized in Table III.

In the 21 cases of Type I, including three with pyloric stenosis and two with highly advanced cancer, all showed good general conditions. A highly advanced cancer means that the tumors were widely disseminated, accompanying ascites or wide metastasis, the cancer was so advanced that no other operation than mere exploratory laparotomy or total gastrec- 
tomy was performed.

The four Type II cases were all with highly advanced cancer, including one that had to be subjected to total gastrectomy and another case for whom we could undertake only exploratory laparotomy. The liver function was slightly disturbed in two cases.

In these cases the $\beta$-globulin value was always reduced, though moderately $(38.7 \%-41.6 \%$, averaging $40.0 \%)$ but the $\zeta$-globulin value rose always above 22.7 percent averaging 29.0 percent, and in particular, went up extremely to high values in two cases $(33.3 \%$ and $37.2 \%)$.

Of the 12 Type III cases, two showed good enough general conditions, but in the other 10 cases, the general conditions were badly deteriorated, of which four were subjected to total gastrectomy and two to exploratory laparotomy. The liver function was slightly disturbed in three cases.

In these cases, the $\beta$-globulin value was always low $(43.6 \%-36.1 \%$, averaging $40.9 \%$ ) but the $\gamma$-globulin value was high $(13.5 \%-20.2 \%$, averaging $16.8 \%$ ).

The mean $\beta$-globulin value in these cases was reduced by 7.2 percent (or dropped by $13.1 \%$ in rate) and the mean globulin value was raised by 6.1 percent (or by $57.0 \%$ in rate) as compared with the values of the mild cases.

Of the seven cases of Type IV, one was rather good in general conditions, but in the others, the cancer was highly advanced, including one case with hemorrhagic cancer and four that had to undergo total gastrectomy.

TABLE III

Liver Protein Fraction Values in Gastric Cancer Cases

\begin{tabular}{|c|c|c|c|c|c|c|}
\hline \multirow{2}{*}{$\begin{array}{l}\text { Type of } \\
\text { cases }\end{array}$} & \multirow{2}{*}{$\begin{array}{c}\text { Number } \\
\text { of } \\
\text { cases }\end{array}$} & \multicolumn{5}{|c|}{ Fraction values (average, \%) } \\
\hline & & Albumin & $\alpha$-Glob. & $\beta$-Glob. & $\zeta$-Glob. & $\gamma$-Glob. \\
\hline Type I & 21 & $(4.2 \sim 8.0)$ & $\begin{array}{c}17.6 \\
(13.5 \sim 19.3)\end{array}$ & $\begin{array}{c}45.7 \\
(45.3 \sim 47.2)\end{array}$ & $\begin{array}{c}19.6 \\
(17.0 \sim 20.6)\end{array}$ & $\left(\begin{array}{l}10.6 \\
(7.0 \sim 11.8)\end{array}\right.$ \\
\hline Type II & 4 & $(2.5 \sim 7.7)$ & $\begin{array}{c}15.9 \\
(14.4 \sim 20.3)\end{array}$ & $\begin{array}{c}40.0 \\
(38.7 \sim 41.6)\end{array}$ & $\begin{array}{c}27.0 \\
(22.7 \sim 37.2)\end{array}$ & $\begin{array}{c}9.9 \\
(6.8 \sim 12.3)\end{array}$ \\
\hline Type III & 12 & $\begin{array}{c}5.9 \\
(3.1 \sim 7.5)\end{array}$ & $\begin{array}{c}16.2 \\
(12.3 \sim 21.8)\end{array}$ & $\begin{array}{c}40.9 \\
(36.1 \sim 43.6)\end{array}$ & $\begin{array}{c}20.2 \\
(17.0 \sim 22.2)\end{array}$ & $\begin{array}{c}16.8 \\
(13.5 \sim 20.2)\end{array}$ \\
\hline Type IV & 7 & $(10.2 \sim 12.1)$ & $\begin{array}{c}16.0 \\
(12.4 \sim 20.3)\end{array}$ & $\begin{array}{c}37.8 \\
(31.6 \sim 42.5)\end{array}$ & $\begin{array}{c}17.2 \\
(13.2 \sim 19.3)\end{array}$ & $\begin{array}{c}18.1 \\
(14.4 \sim 26.7)\end{array}$ \\
\hline Type V & 6 & $\begin{array}{c}14.9 \\
(11.4 \sim 20.3)\end{array}$ & $\begin{array}{c}19.6 \\
(17.0 \sim 22.5)\end{array}$ & $\begin{array}{l}36.3 \\
(31.2 \sim 39.1)\end{array}$ & $\left(\begin{array}{l}19.9 \\
(17.7 \sim 22.0)\end{array}\right.$ & $\begin{array}{c}9.3 \\
(7.0 \sim 11.2)\end{array}$ \\
\hline
\end{tabular}

In these cases the albumin value was always raised $(10.2 \%-12.1 \%$, averaging $10.9 \%$ ), the $\beta$-globulin value was lowered $(42.5 \% \sim 31.6 \%$, 
averaging $37.8 \%$ ) and the $\gamma$-globulin was found risen $(14.4 \%-26.7 \%$, averaging $18.1 \%$ ). In the case with hemorrhagic cancer, in particular, the albumin value registered 11.2 percent, the $\beta$-globulin, value 33.6 percent and the $\gamma$-globulin value 26.7 percent, manifesting a very peculiar tendency.

In comparison with the mean value of mild cases, the mean albumin value in these seven cases was higher by 5.1 percent (or by $87.9 \%$ in rate), that of $\beta$-globulin was lower by 7.4 percent (or by $19.7 \%$ in rate) and that of $\gamma$-globulin higher by 7.4 percent (or $69.1 \%$ in rate). The liver function was slightly disturbed in one case only.

In the seven cases of Type $V$, the cancer was highly advanced and the general conditions were also deteriorated. Two of them were operated upon for total gastrectomy and two others for exploratory laparotomy. The liver function was slightly disturbed in three cases.

In these cases, the albumin value was always over 11.4 percent averaging 14.9 percent and in one case the particularly high level of 20.3 percent was observed, while the $\beta$-globulin value was always low $(31.2 \%-39.1 \%$, averaging $36.3 \%$ ).

In comparison with the values of mild cases, the mean albumin value was higher by 9.1 percent in absolute value (or by $156.8 \%$ in rate) and the mean $\beta$-globulin value was lower by 10.8 percent (or by $22.9 \%$ in rate).

In the above 50 cases of gastric cancer, 21 showed liver protein fraction picture of Type I, four that of Type II, 12 that of Type III, seven that of Type IV and six that of Type V. Sixteen of the 25 cases $(64 \%)$ of Types $I$ and II showed good general conditions, while 23 of the 25 cases (92\%) of Types III, IV and V had complications or highly advanced cancer.

III. Comparison of liver protein fraction picture in gastritis-ulcer cases and gastric cancer cases

The values in the two groups of such cases are summarized in Table IV.

The Type I cases occupied a bare majority of 26 among 50 gastritisulcer cases $(52 \%)$, but among the 50 cancer cases 21 of Type I cases were found $(42 \%)$, a smaller number than among the former.

The Type II cases accounted for 8 percent only in both the groups.

The Type III cases represented 24 percent (12 among 50) in the cancer group, while in the gastritis-ulcer cases 14 percent ( 7 among 50) were of this type; thus, among the former, the cases with low $\beta$-globulin and high $\gamma$-globulin were more frequent than among the latter.

The Type IV cases were somewhat more frequent in the gastritisulcer group (9 or 18\%) than among the gastric cancer cases (7 or $14 \%$ ), while of Type $\mathrm{V}$ cases, the reverse was the case ( 4 or $8 \%$ in the former and 6 or $12 \%$ in the latter groups). 
TABLE IV

Comparison of Liver Protein Fraction Picture in Gastritis-ulcer Cases and Gastric Cancer Cases

\begin{tabular}{|c|c|c|c|c|c|}
\hline Type $\rightarrow$ & I & II & III & IV & V \\
\hline $\begin{array}{l}\text { Gastritis-ulcer } \\
\text { (50 cases) }\end{array}$ & $\begin{array}{c}26 \\
(52.0 \%)\end{array}$ & $\begin{array}{c}4 \\
(8.0 \%)\end{array}$ & $\begin{array}{c}7 \\
(14.0 \%)\end{array}$ & $\begin{array}{c}9 \\
(18.0 \%)\end{array}$ & ( $8.0 \%)$ \\
\hline $\begin{array}{l}\text { Gastric cancer } \\
(50 \text { cases })\end{array}$ & $\begin{array}{c}21 \\
(42.0 \%)\end{array}$ & $\begin{array}{c}4 \\
(8.0 \%)\end{array}$ & $\begin{array}{c}12 \\
(24.0 \%)\end{array}$ & $\begin{array}{c}7 \\
(14.0 \%)\end{array}$ & $\begin{array}{c}6 \\
(12.0 \%)\end{array}$ \\
\hline
\end{tabular}

\section{Discussion AND Conclusions}

Recently, with the advance in filter-paper electrophoresis, studies on electrophoretic studies on tissue protein have increased, but there is no report on a clinical study of the liver protein, so far as we known.

We have herein presented the findings on the albumin, and the a-, $\beta-, \zeta-$ and $;$-globulin contents in the protein extracted from the liver of 108 surgical gastric disease cases, as fractioned by electrophoresis and identified by the methods described in Report I.

Of the 108 cases, eight showed very good general conditions, their red cell count, hemoglobin content and hematocrit value were all within the normal range, and their liver function was also normal; we took these mild gastric disease cases as controls in this study. Of their liver protein fraction, albumin was present only in a very small quantity (mean value : $5.8 \%$ ) while the globulins occupied a very large part (mean value : $94.2 \%$ ) and among these, $\beta$-globulin was most abundant.

Demling et al. ${ }^{2}$ divided the cellular components into three parts and by paper-electrophoretically fractionating of the protein in these parts, they found the mean values of 4.87 percent of albumin, 15.66 percent of $\alpha$-globulin, 55.67 percent of $\beta$-globulin and 23.78 percent of $\gamma$-globulin. Their method of extracting protein was not the same as ours, but their findings on the smallness of the albumin content and the great predominance of globulins may be deemed as similar to our results cited above.

Luck $^{3)}$ and Urban ${ }^{4}$ also proved that the liver protein consists in the greatest part of globulin, by the biochemical method.

In our study on the protein fractions of 100 cases except for the eight above, we attempted a classification into five types with the changes in the $\beta$-globulin content as the main criterion.

Among the 50 cases of each of gastritis or gastric ulcer and of gastric cancer, 24 of the 30 Types I and II cases of the former (80\%) and 16 of 25 Types I and II cases of the latter (64\%) showed good general conditions.

But the Types III, IV and V cases were in the majority cases with 
bad general conditions, having hemorrhage or pyloric stenosis in complication (18 of 20 cases or $90 \%$ among the gastritis-ulcer cases and 16 of 25 cases or $64 \%$ of gastric cancer cases).

Thus, among the cases of gastric diseases, those with the liver protein fraction picture within the range of the control values of mild cases were generally good in general conditions, while those with the picture of reduced $\beta$-globulin and augmented $\gamma$-globulin and/or albumin were usually cases with complications or advanced diseases.

Demling et $a l .{ }^{2)}$ in their experiments with rats, have demonstrated that $\beta$-globulin in the liver protein was markedly reduced in the cases with general disturbances due to poisons. We found a similar tendency in our clinical cases.

It must be noted that such a tendency is more marked in the cases of hemorrhagic ulcer than in those with gastric cancer.

$\mathrm{Ohi}^{5}$ ) and Le Veen ${ }^{6}$ report that bleeding in the stomach causes several functional and morphological disturbances to the liver than peripheral bleeding. We found no marked liver disturbances by our clinical liver function tests in our cases with gastric hemorrhage, but in our liver protein electrophoresis, we found a tendency specific to them, so that from the angle of liver protein we can make inference on the specific effect of gastric hemorrhage.

In the last place, we found that the cases belonging to our Type I with their liver protein fraction contents within the range of the control values were somewhat more frequent among the gastritis-ulcer cases $(52 \%)$ than among the gastric cancer cases ( $42 \%$ ), while these belonging to the Types III, IV and V with the $\beta$-globulin value lower, the $\gamma$-globulin and/or the albumin value higher than the controls were somewhat more numerous among the latter $(50 \%)$ than among the former $(40 \%)$, this tendency being most marked among the Type III cases (24\% among the gastric cancer and $14 \%$ among the gastritis-ulcer cases). The slightly higher frequency of IV cases among the gastritis-ulcer cases may be due to the five hemorrhagic ulcer cases among the nine Type IV cases.

\section{SumMary}

By means of our electrophoretic method applied to analyse the liver protein, as reported in Part I of this series, we studied the liver protein fractions in eight cases of chronic gastritis and 50 cases each of gastric or duodenal ulcer and of gastric cancer. The results obtained were as follows :

1. The liver protein in two cases of chronic gastritis and six of gastric ulcer, but only in mild grade as diagnosed clinically, was found to contain only a very small quantity of albumin $(5.8 \%$ on the average), the remainder being all globulins, $\beta$-globulin being particularly abundant $(47.1 \%$ on 
the average).

2. Of the severe cases of gastric diseases, the cases showing the liver protein fraction values within the range of the above mild cases were generally of good general conditions, but those with lowered $\beta$-globulin, raised $;$-globulin and/or albumin value were usually cases with complications or advanced disease.

3. The liver protein fraction values were more frequently within the values of mild cases in gastritis-ulcer cases than in gastric cancer cases, and the $\beta$-globulin value was lowered, the $r$-globulin and/or the albumin value raised more frequently among the gastric cancer cases.

\section{References}

1) Sato et al., Tohoku J. Exp. Med., 1958, 68, 193.

2) Demling et al., K1. Wochschft., 1953, 31, 1103.

3) Luck, Cold Spring Harber Symposia on Quantit. Biol., 1950, 14, 127.

4) Urban, Biochem. Z., 1936, 283, 435.

5) Ohi, Rinsho-Geka (Jap.), 1955, 10, 857.

6) Le Veen et al., Surg. etc., 1952, 94, 433. 